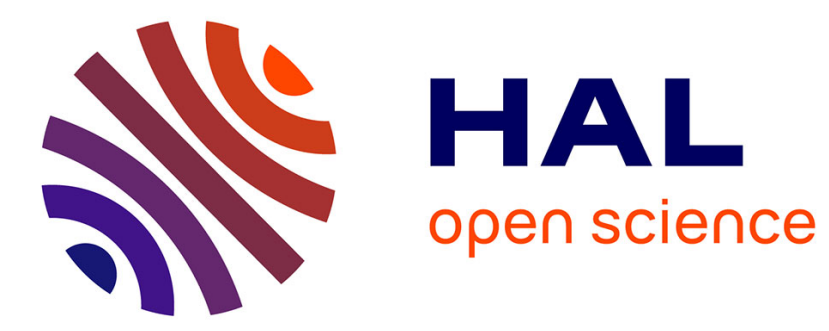

\title{
A comprehensive protocol for chemical analysis of flame combustion emissions by secondary ion mass spectrometry
}

Cornelia Irimiea, Alessandro Faccinetto, Yvain Carpentier, Ismael-Kenneth Ortega, Nicolas Nuns, Eric Therssen, Pascale Desgroux, Cristian Focsa

\section{To cite this version:}

Cornelia Irimiea, Alessandro Faccinetto, Yvain Carpentier, Ismael-Kenneth Ortega, Nicolas Nuns, et al.. A comprehensive protocol for chemical analysis of flame combustion emissions by secondary ion mass spectrometry. Rapid Communications in Mass Spectrometry, 2018, 32 (13), pp.1015-1025.

10.1002/rcm.8133 . hal-02315159

\section{HAL Id: hal-02315159 \\ https://hal.science/hal-02315159}

Submitted on 14 Oct 2019

HAL is a multi-disciplinary open access archive for the deposit and dissemination of scientific research documents, whether they are published or not. The documents may come from teaching and research institutions in France or abroad, or from public or private research centers.
L'archive ouverte pluridisciplinaire HAL, est destinée au dépôt et à la diffusion de documents scientifiques de niveau recherche, publiés ou non, émanant des établissements d'enseignement et de recherche français ou étrangers, des laboratoires publics ou privés. 


\title{
A comprehensive protocol for chemical analysis of flame combustion emissions by Secondary Ion Mass Spectrometry
}

Cornelia Irimiea ${ }^{1,2, \dagger}$, Alessandro Faccinetto ${ }^{1, *}$, Yvain Carpentier ${ }^{2}$, Ismael-Kenneth Ortega $^{3}$, Nicolas Nuns ${ }^{4}$, Eric Therssen ${ }^{1}$, Pascale Desgroux ${ }^{1}$, Cristian Focsa ${ }^{2}$

${ }^{1}$ Univ. Lille, CNRS, UMR 8522 - PC2A - Laboratoire de Physico-Chimie des Processus de Combustion et de l'Atmosphère, F-59000 Lille, France.

${ }^{2}$ Univ. Lille, CNRS, UMR 8523 - PhLAM - Laboratoire de Physique des Lasers, Atomes et Molécules, F-59000 Lille, France.

${ }^{3}$ ONERA - The French Aerospace Laboratory, F-91123 Palaiseau, France.

${ }^{4}$ Univ. Lille, CNRS, UMR 2638, Institut M. E. Chevreul, F-59000 Lille, France.

${ }^{\dagger}$ Currently affiliated to ${ }^{3}$.

*Correspondence to: alessandro.faccinetto@univ-lille1.fr

\begin{abstract}
RATIONALE. Time of flight secondary ion mass spectrometry (ToF-SIMS) is used to provide detailed information on the surface chemical composition of soot. An analytical protocol is proposed and tested on a laboratory flame, and the results are compared with our previous measurements provided by two-step laser mass spectrometry (L2MS).

METHODS. This work details: (1) the development of a dedicated apparatus to sample combustion products from atmospheric flames and deposit them on substrates suitable for ToF-SIMS analysis; (2) the choice of the deposition substrate and the material of the sampling line, and their effect on the mass spectra; (3) a method to separate the contributions of soot and condensable gas based on impact deposition, and finally (4) the post-acquisition data processing.
\end{abstract}

RESULTS. Compounds produced during flame combustion are detected on the surface of different deposition substrates and attributed a molecular formula based on mass defect analysis. Silicon and titanium wafers perform similarly, while the surface roughness of glass microfiber filters results in a reduced mass resolution. The mass spectra obtained from the analysis of different locations of the deposits obtained by impaction show characteristic patterns that are attributed to soot/condensable gas.

CONCLUSIONS. A working method for the analysis of soot samples and the extraction of useful data from mass spectra is proposed. This protocol should help avoiding common experimental issues like sample contamination, while optimizing the setup performance by maximizing the achievable mass resolution.

Keywords: ToF-SIMS, soot, sampling protocol, mass defect, data reduction. 


\section{Introduction}

Time of flight secondary ion mass spectrometry (ToF-SIMS) is an analytical technique used to probe the composition (elemental and/or molecular) of any predefined micro-volume from any solid surface by sputtering the sample with a primary ion beam, then mass-analyze the secondary ions ejected from the surface with a time of flight mass spectrometer. The strength of ToF-SIMS is its ability to identify unknown species when little to any a priori knowledge of the sample is available. For this very reason, in the last decade ToF-SIMS has been successfully applied to many fields, e.g. material and Earth sciences and biosciences ${ }^{[1]}$. Dedicated commercial versions can nowadays be purchased as standard laboratory equipment, while both commercial and freeware software for the reduction and interpretation of the mass spectra are readily available. However, despite the recent developments, there are still many issues and challenges when it comes to the analysis of complex samples and quantitative measurements. In particular, the fast dissociation of the parent ions generated after the surface sputtering, especially occurring in samples with a high organic content, potentially limits the access to a complete chemical characterization of the samples ${ }^{[2]}$.

Combustion processes release in the troposphere a wide array of pollutants among which particulate matter (soot) is well known to have detrimental effects on the environment that range from impacting the radiative balance of the atmosphere ${ }^{[3,4]}$ to desorbing harmful compounds inside the lungs after being inhaled. To date, detailed knowledge on the formation process of soot and on the chemical composition of the soot particles found in the atmosphere is not fully available. Airborne particles are usually collected directly from the exhausts or from urban and rural areas after aging in the atmosphere ${ }^{[2,5-7]}$. Then, they are analyzed using a variety of techniques like online aerosol mass spectrometry (AMS) or ex-situ two-step laser mass spectrometry (L2MS) with the aim of identifying the pollutants formed during the combustion and/or aging process ${ }^{[8-11]}$. Generally, ToF-SIMS is not the technique of choice when it comes to soot characterization. In order to be analyzed, soot aerosols have to be sampled and deposited on a solid substrate. Hence, the analysis is obviously limited to the stable compounds that can survive degradation during the time required for the transfer of the samples to the analysis facility. Despite such limit, we believe that ToF-SIMS provides substantial benefits for the characterization of samples containing soot particles and precursors as polycyclic aromatic hydrocarbons (PAHs). Such benefits include the ability to probe a layer as thin as $1 \mathrm{~nm}$ on the sample surface, thus giving direct detailed molecular information on the surface chemical composition as opposed to the bulk information obtainable by other techniques. Furthermore, the high mass resolution that can typically be achieved from the ion extraction occurring from a flat surface is only possible when analyzing solid samples. As discussed in this work, the higher mass resolution enables for mass defect analysis that is a powerful tool to identify unknown species from a mass spectrum ${ }^{[12]}$. In particular, in this work we propose an analytical protocol to analyze soot aerosols that can be applied either to combustion fundamental research or environmental sciences. We compare soot samples obtained on three different solid substrates (glass microfiber filters, silicon and titanium wafers), we assess the effect of the sampling line material on the structure of the mass spectra (stainless steel, conductive tubing for aerosol transport), and finally we discuss an experimental approach to separate the soot particulate from the condensable gas in the aerosol during the ToF-SIMS analysis. The results are compared to our previous investigations by L2MS. 


\section{Experimental setup}

\subsection{Burner and sampling system}

A laminar diffusion methane flame (DIF-S for short) is used as a soot generator. The flame is stabilized at atmospheric pressure on a custom burner similar to that used by Shaddix et $a l .{ }^{[13]}$ and more recently by Tian et $a l^{[14]}$ The burner is equipped with a $9.4 \mathrm{~mm}$ inner diameter central injector supplied with $0.52 \mathrm{~L} \mathrm{~min}^{-1}$ of $\mathrm{N} 5.0$ grade methane. The injector is surrounded by a ring-shaped $88 \mathrm{~mm}$ outer diameter chamber for the air shield. To obtain a homogeneous gas shield, the chamber is filled with mineral wool covered with glass beads and the air enters the bottom of the chamber from three ports spaced at $120^{\circ}$. To improve the flame stability during the measurements, a large shielding flow is required $\left(86.6 \mathrm{~L} \mathrm{~min}^{-1}\right.$ of air) that results in a $11.5 \mathrm{~cm}$ high non-smoking flame. To minimize any perturbations from the environment, a quartz windowed chimney is installed on the top of the burner as shown in Figure 1a. Laminar diffusion flames similar to flame DIF-S have been subject of many in-situ investigations by laser induced incandescence/fluorescence (LII/LIF) ${ }^{[15,16]}$ for real time monitoring of soot volume fraction and soot precursors ${ }^{[13,14]}$. A flame sampling technique is developed as detailed below. Flame DIF-S is sampled in the axis, roughly mid-flame at $65 \mathrm{~mm}$ height above the burner.

To quickly cool down soot and combustion gas extracted from the flame and to quench post-sampling chemical reactions and limit particle aggregation, an extraction system featuring high dilution ratio is developed. The extraction system consists of a sampling microprobe coupled to an automatic pressure regulation system as shown in Figure 1b, engineered to combine high dilution ratio while minimizing flame perturbations. The extraction system is a further development of the apparatus that we first tested in Betrancourt et $a l .{ }^{[17]}$. Briefly, the microprobe is made of two co-annular quartz tubes that define the aerosol path. The outer tube has $14 \mathrm{~mm}$ OD, $2 \mathrm{~mm}$ thickness, while the inner tube has $8 \mathrm{~mm}$ OD, $1 \mathrm{~mm}$ thickness. The outer tube ends with a $20 \mathrm{~mm}$ long thin tip on which an orifice is obtained by erosion with emery polishing paper. The incertitude on the aperture diameter is determined by means of calibrated wires. A nitrogen dilution flow (typically $0.5-20 \mathrm{~L} \mathrm{~min}^{-1}$ ) enters the microprobe side port and flows between the two quartz tubes up to the probe tip. A sample flow from the flame enters the microprobe tip orifice drawn in by the room-probe pressure difference. The sample flow and dilution nitrogen mix in the small chamber at the probe tip and are quickly removed into the pumping flow through the inner tube. The automatic pressure regulation system is located downstream the microprobe, and consists of a HEPA filter, a Pfeiffer CMR261 pressure gauge, a Pfeiffer EVR116 automatic regulation valve and a pumping unit, as shown in Figure $1 b$. The automatic regulation valve uses a proportional-integral-derivative (PID) control loop feedback to maintain the pressure in the sampling line within 0.5 mbar from the set point. The pressure differential $\Delta p$ between the sampling line (thus the microprobe) and the room (thus the flame) is typically set in the range 30-50 mbar depending on the required dilution. The larger the $\Delta p$ the more efficient the extraction from the flame (soot and gas concentration in the sampling line increases), but also the larger the particle aggregation and vapor condensation rates in parallel. The $\Delta p$ was limited below 50 mbar to avoid flame perturbation and to reduce the flame sampled volume. In particular, improvements with respect to Betrancourt et al. ${ }^{[17]}$ include:

- increased the probe orifice diameter up to $500 \pm 50 \mu \mathrm{m}$ to be able to sample flame DIF-S (sooting flame) without clogging the probe , typically 5-10 min;

- replaced the conducting tubing for aerosol transport with stainless steel tubing to avoid polysiloxane contamination (see Results and Discussion); 
- implemented a homemade impactor used for the deposition of soot on substrates suitable for ex-situ analyses.

- calibrated the system for dilution ratio as high as $3 \cdot 10^{4}$. The sampling system is tested and calibrated with a reference ammonium sulfate aerosol. The aerosol is generated in a TSI model 3076 atomizer, dried then injected into a 2 L buffer volume in which the microprobe is introduced through a side port. The particle concentration inside the buffer volume and downstream the probe are monitored in parallel in real time using two condensation particle counters CPC TSI model 3775 , both of them calibrated shortly before the test. With this setup it is possible to reliably calculate the dilution ratio introduced by the probe on the test aerosol as a function of $\Delta p$ and dilution flow.

\subsection{Preparation of samples for surface analysis}

The mass resolution is affected by the surface roughness, therefore the substrates have to be prepared in a way that limit their surface irregularities. This way aerosols can be analyzed after deposition on suitable substrates with a well-defined procedure. This section details the substrate choice, the employed cleaning protocol and the deposition method. We compare the mass spectra obtained by deposition of soot and condensable gas on glass microfiber filters that allows high efficiency particle collection with those obtained from the impaction on ultra-flat silicon and titanium wafers that enables for the maximum mass resolution. Filters and wafers are first decontaminated then used as substrates for soot deposition.

\subsubsection{Substrate decontamination}

Binder-free, glass microfiber Whatman filters having $21 \mathrm{~mm}$ diameter, $0.26 \mathrm{~mm}$ thickness $\left(52 \mathrm{~g} \mathrm{~m}^{-2}, 0.7 \mu \mathrm{m}\right.$ smallest pore size) are purchased from Fisher Scientifics. Silicon (100) wafers 10x10x0.5 mm optically polished on one side are purchased from PI-KEM Ltd. Grade 5 titanium alloy wafers (90\% titanium, $6 \%$ aluminum, $4 \%$ vanadium) 10x10x0.5 mm optically polished on one side are purchased from Optics Concept. All chemicals employed in the surface cleaning protocols detailed below are $99.5 \%$ or higher purity and purchased from Sigma-Aldrich.

The glass microfiber filters are washed with dichloromethane then heated up to $250^{\circ} \mathrm{C}$ for 12 hours before sampling in order to reduce surface contamination and finally transferred to the sample holders.

Silicon and titanium wafers are pre-cleaned with ethanol-wet optical paper then specific protocols are employed to increase the thickness of the passivating oxides and remove surface contaminations.

Silicon wafers are further decontaminated by RCA cleaning ${ }^{[18]}$ that consists of two steps during which oxidative desorption with hydrogen peroxide/ammonium hydroxide (RCA1) is followed by complexation with hydrogen peroxide/hydrochloric acid (RCA2). The wafers are first immersed in the RCA1 solution contained into a large crystallizer $(325 \mathrm{~mL}$ ultrapure water, $65 \mathrm{~mL}$ of ammonia solution $27 \% \mathrm{w} / \mathrm{w}$ and $65 \mathrm{~mL}$ of hydrogen peroxide $30 \% \mathrm{w} / \mathrm{w}$ ) heated up to $70^{\circ} \mathrm{C}$ for $20 \mathrm{~min}$, rinsed five times with ultrapure water. The wafers still wet are transferred in a second crystallizer containing the RCA2 solution $(300 \mathrm{~mL}$ ultrapure water, $50 \mathrm{~mL}$ of hydrochloric acid $36 \% \mathrm{w} / \mathrm{w}$ and $50 \mathrm{~mL}$ of hydrogen peroxide $30 \% \mathrm{w} / \mathrm{w}$, heated up to $70^{\circ} \mathrm{C}$ ) for $20 \mathrm{~min}$ then rinsed with ultrapure water. 
Titanium wafers are further decontaminated by nitric acid cleaning. The wafers are immersed in the cleaning solution contained into a large crystallizer $(50 \mathrm{~mL}$ ultrapure water and $50 \mathrm{~mL}$ of nitric acid $70 \% \mathrm{w} / \mathrm{w}$ ) and heated up to $60^{\circ} \mathrm{C}$ for $20 \mathrm{~min}$.

All wafers are finally rinsed five times with ultrapure water then dried by gradually heating them up to $50^{\circ} \mathrm{C}$ inside a clean closed crystallizer. Once dry, they are transferred to the sample holders consisting of $3.5 \mathrm{~cm}$ diameter glass Petri dishes for storage. The sample holders are sealed with Parafilm strips to avoid recontamination, and opened only immediately before flame sampling.

\subsubsection{Sampling procedure: soot/condensable gas deposition}

The microprobe used to sample the flame is connected downstream to the sample holders as follows.

Sampling on glass microfiber filters: a custom sample holder for glass microfiber filters is obtained from two KF25 flanges by fitting a disc of porous glass inside the centering ring, and blocking a glass microfiber filter on its surface with a suitable o-ring. The microfiber filter covers the whole line section so that the pumping flow is entirely forced to pass through the filter. Soot particles are trapped between the fibers, while condensable gas deposit/adsorb on the fibers surface as well as on the already deposited soot.

Sampling on wafers: the sample holder for wafers is a custom homemade impactor. The wafer is fixed on a supporting metal grid $1.0 \mathrm{~mm}$ from the very end of the inner metal tube that transports the soot-laden flow. The wafer covers around one third of the sampling line cross section, and no appreciable difference in the line pressure drop can be measured with or without it. Soot particles and condensable gas impact the wafer at around $30 \mathrm{~m} \mathrm{~s}^{-1}$ flow velocity, and generate a thin layer of deposited materials on its surface.

A bypass line is installed in both cases to allow a pre-sampling pumping of the main line and the easy replacement of the filters/wafers without affecting the line pressure and temperature, and to avoid cross-contamination of the samples. The sampling time for flame DIF-S is 3 min per deposition.

\subsection{Two-step laser mass spectrometry (L2MS)}

The custom developed L2MS apparatus has been described in detail elsewhere ${ }^{[19,20]}$. Briefly, a Nd:YAG laser beam (Quantel Brilliant, $4 \mathrm{~ns}, 532 \mathrm{~nm}, 10 \mathrm{~Hz}$ ) is focused to a $0.2 \mathrm{~mm}^{2}$ circular spot on the surface of the sample that is placed in the ion source of the mass spectrometer $\left(10^{-8}\right.$ mbar residual pressure) on a cryogenic stage. Neutral species in the desorption plume are then ionized by an orthogonal laser beam (Continuum Powerlite, $6 \mathrm{~ns}$, $266 \mathrm{~nm}, 10 \mathrm{~Hz}$ ), and mass analyzed in a custom Jordan ToF Products Inc. $1.72 \mathrm{~m}$ long reflectron ToF-MS (maximum resolving power is $\sim 1500$ ). The ion detector signals are recorded using a $2 \mathrm{GHz}$ digital oscilloscope LeCroy Waverunner 6200A. Both desorption and ionization irradiances are kept close to the threshold (typically several $\mathrm{MW} \mathrm{cm}^{-2}$ ) to avoid post-ionization dissociation of the analytes. L2MS mass spectra are averaged over 25 desorption spots on the same sample surface.

\subsection{Time of flight secondary ion mass spectrometry (Tof-SIMS)}

To gain information on the surface chemical composition of soot and gas deposited/condensed on the samples, a protocol that makes use of the commercial ION-TOF GmbH apparatus ToF.SIMS ${ }^{5}$ available at the Surface Analysis Platform at Univ. Lille is 
developed $^{[21]}$. The theoretical maximum resolving power of the mass spectrometer is $\sim 10^{4}$. The instrument can be operated in either static or dynamic mode. The two modes are delimited by the value of the total ion dose which is set to $10^{13}$ ions $\mathrm{cm}^{-2[22]}$. A total ion dose below this threshold (static mode) is considered to provide no more than one ion to the top surface layer of atoms and molecules, and this classifies this technique as suitable for soot surface analysis without loss of chemical information of the parent molecules due to post-ionization dissociation reactions. Our main interest is the organic content and in this case $\mathrm{Bi}_{3}{ }^{+}$is the appropriate primary ion gun to be used ${ }^{[22]}$. The static mode is used to obtain mass spectra of selected regions from the sample surface by irradiating it in random mode at $25 \mathrm{kV}$. The acquisition is performed using 130 scans/acquisition (300 s) on a $500 \times 500 \mu \mathrm{m}^{2}$ surface, with $256 \times 256$ pixels image resolution. An electron flood gun is used for the surface charge compensation whenever insulating substrates like glass microfiber filters are analyzed. These settings lead to an ion dose of $\sim 10^{11}$ ions $\mathrm{cm}^{-2}$, well below the threshold of SIMS static mode. Multiple zones from the sample surface are scanned in positive polarity. Some contamination between samples is observed when analyzing multiple samples, therefore we recommend analyzing one sample at a time.

\subsubsection{Post-acquisition data processing}

Data pre-processing is used to correct or minimize some acquisition issues before analyzing mass spectra, like instrument miscalibration and background noise. In this work the mass spectra are calibrated, smoothed and aligned. Then, the signal peaks are selected and built into a peak list and attributed a molecular formula by mass defect analysis.

\section{Mass calibration}

Easily identified $\mathrm{C}^{+}, \mathrm{CH}^{+}$and $\mathrm{CH}_{2}{ }^{+}$are used for a first mass calibration, and later replaced by other carbon-hydrogen ions selected because of their symmetrical shape and roughly equally spaced on the $\mathrm{m} / \mathrm{z}$ range of interest. Internal consistency of the mass calibration is verified by double checking the $\mathrm{m} / \mathrm{z}$ of some polyaromatic hydrocarbon molecular ions well known to form into flames $\left(\mathrm{C}_{10} \mathrm{H}_{8}{ }^{+}, \mathrm{C}_{16} \mathrm{H}_{10}{ }^{+}\right.$and $\mathrm{C}_{24} \mathrm{H}_{12}{ }^{+}$to name a few $)$after every addition of a new mass calibration peak.

\section{Mass resolution and effect of the deposition substrate}

The achieved mass resolution calculated at the full width of the peak at half its maximum height (FWHM) is in the range [1000, 2500] for depositions on glass microfiber filters, and $[6000,7500]$ for depositions on wafers ( $\mathrm{Si}$ or $\mathrm{Ti}$ ). The comparison between the two mass spectra obtained from soot deposited on microfiber glass filters and Si wafers as well as the Gaussian fit of the identified peaks are shown in Figure 2. In particular, the mass spectra obtained from deposition on wafers give access to additional information and improve the confidence level on the determination of the accurate mass, while depositions on microfiber glass filter result in a much poorer accuracy. There is no significant difference between samples deposited on silicon and titanium wafers once the mass spectra are normalized and the blank peaks are removed.

\section{Smoothing}

Being the primary purpose of the data reduction the measurement of both the accurate mass $(\mathrm{m} / \mathrm{z}$ value of the center of the peaks) and the peak integrated area, a low smooth ratio algorithm is preferred to avoid excessive peak height reduction. A satisfying compromise 
between noise reduction and peak height reduction is found with a fast Fourier transform algorithm (FFT), five points sampling (corresponding to $105 \mathrm{~Hz}$ cutoff frequency) that efficiently removes the high frequency noise in exchange of approximately $5 \%$ reduction of the peak intensity. A baseline correction is not deemed necessary.

\section{$m / z$ alignment}

A common issue in high resolution mass spectrometry is the systematic shift between the time of flight and the observed $\mathrm{m} / \mathrm{z}$ that is often due to poor calibration or slight changes in the analytical parameters over different acquisitions. Therefore, systematic shifts sometimes appear in repeated acquisitions that might result in the same compound to be attributed different accurate mass. To minimize this uncertainty, the $\mathrm{m} / \mathrm{z}$ axes are re-scaled and shifted in order to maximize the correlation between different samples and the calculated $\mathrm{m} / \mathrm{z}$ of a group of reference peaks. The pattern of carbon fragment ions at low $m / z$ and PAHs is assessed from the analysis of PAHs standards, and can be used as a reference to align the peak sequence.

\section{Normalization}

Systematic differences in the amount of desorbed and ionized compounds are common and may originate from a variety of sources: different sample size, preparation, inconstancy of the acquisition parameters, etc. The overall result is a fluctuation of the ion count. To compensate at least partially for these differences, the mass spectra are normalized to the partial ion count calculated on the selected peak list only (discussed in the following section), after discarding any signal attributed to the blank (mostly organosilicon or organotitanium compounds). The blanks are filters/wafers cleaned as detailed above. This approach is deemed necessary to compare samples deposited on substrates having different chemical composition and thus very different background signals and intensities.

\section{Background subtraction and peak finding}

A peak finding algorithm based on second derivative filtering is used to automate the peak finding procedure. The automatically generated peak list is then manually refined based on the comparative analysis of samples obtained from different substrates as detailed below.

The reactivity of soot and condensable gas at the substrate surface is not completely negligible, especially in the case of depositions on silicon and titanium wafers, and peak signals corresponding to some reaction products are well distinctive of the substrate material. Although organotitanium compounds are easily identified courtesy of titanium's very distinctive isotopic pattern and large negative mass defect (see below), organosilicon compounds tend to effectively overlap carbon and carbon-oxygen compounds and sometimes can be tricky to identify.

As shown in Figure 3, the reactivity between the combustion products and the substrate is taken into account during the peak selection process, and its magnitude is assessed from the comparative analysis of the mass spectra obtained from deposition on silicon (solid line) and titanium (dashed line) wafers. Three classes of signals are therefore identified: peak signals only occurring on silicon or titanium wafers are mostly attributed to organosilicon or organotitanium compounds. Signals occurring on both depositions are attributed to combustion products and are only considered for the mass defect analysis. Incidentally, the need for this protocol highlights how silicon is a rather poor choice as a substrate for depositions since the reactivity $\mathrm{C}$-Si generates a large number of byproducts that overlap the 
combustion products in the mass spectra and therefore heavily interfere with the peak identification and area integration. Once the substrate-specific peaks are removed, the substrate chemical composition does not seem to play any other role on the structure of the peak sequence.

Accurate mass and peak integrated areas are obtained from Gaussian fits using the freeware ToF Tools platform ${ }^{[23]}$. The peak deconvolution in the range $m / z=476-478$ is shown in Figure 2. A mass spectrum obtained in the same experimental conditions on glass microfiber filter is also shown for comparison. The uncertainty on the determination of the accurate mass is estimated as the standard deviation of at least three measurements performed on the surface of the same sample.

\section{Results and discussion}

Five different samples are collected in the same flame conditions, and five zones are analyzed at the surface of each sample for reproducibility tests. The reproducibility of the mass spectra obtained from different surface locations is satisfying when the data post-processing is limited to the signals in the peak list (i.e. attributed to soot). After removal of the blank signals and normalization of the mass spectra by the partial ion count calculated on the peak list, the standard deviation calculated on the five different acquisitions on the same sample is typically the $15-20 \%$ of the average.

\subsection{Soot vs. condensable gas}

High velocity impaction in the range of $30 \mathrm{~m} \mathrm{~s}^{-1}$ results in the soot particles depositing on the wafer surface on a small spot having roughly 3-5 mm diameter as shown in Figure 4a. Figure $4 \mathrm{~b}$ shows an image $500 \times 500 \mu \mathrm{m}^{2}$ on the border of the soot deposit. Soot particles aggregate on the center of the wafer, while condensable gas scatter on the whole wafer surface. Post-analysis data reconstruction allows for the attribution of a mass spectrum to different areas corresponding to the selected regions of interest (ROI). The analysis of a ROI in the soot deposit (Figure 4c) and a ROI on the wafer surface surrounding the soot (Figure 4d) can be exploited for a rough separation of the contributions to the mass spectra of condensable gas and soot particles as explained below. The mass spectra feature different contribution of the molecular ions in the low and high mass region. The condensable gas ROI is dominated by low mass fragment ions in the region $m / z<100$. After normalization, the peak relative intensities differ in the high $\mathrm{m} / \mathrm{z}$ region, with a very low contribution of high mass molecular ions. In general, the soot deposit ROI are significantly richer in high $\mathrm{m} / \mathrm{z}$ masses than the condensable gas ROI, and feature an intensity maximum in the region $m / z \in[200,300]$. Another major difference between the two regions is given by the base peak identified in the high $\mathrm{m} / z$ region that shifts from $\mathrm{C}_{18} \mathrm{H}_{10}{ }^{+}$on the wafer to $\mathrm{C}_{19} \mathrm{H}_{11}{ }^{+}$on the soot spot.

As already mentioned above and shown in Figure 4a, soot accumulates on a spot in front of the impactor aperture and is visually absent anywhere else on the wafer surface. On the other hand, the deposition of condensable gas on the top of already deposited soot cannot be ruled out, especially when considering the high specific surface area of young soot particles. In order to separate the contribution to the mass spectra of soot and condensable gas, a direct subtraction between the two zones is risky since it would likely generate spurious negative and positive peaks. In Betrancourt et al. ${ }^{[17]}$ we showed that the probe is able to sample ultrafine particles as small as $4 \mathrm{~nm}$ for online mobility diameter measurements. However, in this work, to be detected the particles have to deposit on the wafer surface and therefore any 
particle smaller than the cutoff diameter escapes impaction. At the time of this work the cutoff diameter of the custom-made impactor was not known. This way we sampled a reference flame in which the primary particle diameter is known from laser induced incandescence measurements and estimated bellow $4 \mathrm{~nm}$, Bladh et al. ${ }^{[33]}$. The sampling over wafers resulted in depositions reproducible and visible to the naked eye. Accordingly deposition of ultrafine particles is most likely possible because of the occurrence of post-sampling aggregation that shifts their size distribution, above the impactor cutoff diameter. However, it is reasonable to believe that post-sampling aggregation does not affect the surface chemical composition, and therefore ToF-SIMS surface analysis is still expected to be representative of the surface chemical composition of the sampled particles. Furthermore, it is already shown for a premixed flame ${ }^{[32]}$ that the condensed gas phase contains masses as high as $m / z=400$. A similar mass distribution is identified for the zone outside the soot spot in this work (Figure 4d). The small contribution of the masses higher than $\mathrm{m} / \mathrm{z}=400$ may be due to soot aggregates that are trapped within the condensable gas phase.

Although the wafer surface ROI provides chemical information on the condensable gas phase, the contributions to the mass spectra of condensable gas and soot particles cannot be easily separated on the soot deposit ROI. This asymmetry is due to the larger diffusion coefficient of the gas compared to the particles. This approach is a further improvement of our previous works based on deposition on microfiber glass filters ${ }^{[31,32]}$. In particular, soot particles and condensable gas tend to form a homogenous mix on the surface of the glass microfiber filters and as a result their contributions are very tricky to separate. By contrast, the main advantage of impaction is the net separation between the particulate matter that deposits on the central spot, and the condensable gas that can diffuse and deposit all over the wafer surface.

\subsection{Mass defect analysis to identify unknown compounds}

Data pre-processing is used to correct or minimize some of the acquisition issues before analyzing mass spectra data. The mass spectra are calibrated, smoothed and re-aligned as detailed in the methodology section. Then, mass defect analysis allows the assignment of a molecular formula to the selected accurate masses and therefore the definition of a working peak list.

The nuclear binding energy is slightly different for every nuclide, and this is reflected into a different exact mass. Therefore, different atoms, molecules or ions have unique exact mass even if they share the same nominal mass. The mass defect $\Delta$, defined as the difference between the exact mass of an atom, molecule or ion with a given isobaric composition and its nominal mass is also unique and is a powerful tool to identify unknown species ${ }^{[25,26]}$. In principle, this procedure can be extended to any atom, molecule, ion or even cluster once its mass defect is known. The use of mass defect plots has two distinctive advantages. First, each signal peak corresponds univocally to one data point, so that large data sets can be represented in a relatively simple plot. Second, homologous series of peaks line up and important patterns become apparent even for complex mass spectra. From this representation it is possible to associate classes of molecules to the identified species: for instance, in the mass defect plot aliphatic groups have a larger slope (due to the higher number of hydrogen atoms contained into the molecule) while aromatic compounds have a smaller slope (they contain a lower number of hydrogen atoms per carbon atom).

The mass defect plots obtained from the mass spectra in Figure $4 \mathrm{c}$ and $\mathrm{d}$ are shown in Figure $5 . \mathrm{C}_{\mathrm{m}} \mathrm{H}_{\mathrm{n}}{ }^{+}$ions are identified with high confidence by mass defect analysis (accurate 
and exact mass differ by 0.1-5 ppm), and represent the most intense signals. Many signals attributed to $\mathrm{C}_{\mathrm{m}} \mathrm{H}_{\mathrm{n}}{ }^{+}$ions are consistent with $\mathrm{PAH}$ molecular ions.

A sequence of low mass defect compounds emerges below the main $\mathrm{C}_{\mathrm{m}} \mathrm{H}_{\mathrm{n}}{ }^{+}$sequence. The identification of these signals is not yet conclusive since the lower mass defect can be due to the presence of more oxygen atoms or fewer hydrogen atoms alike. At low $\mathrm{m} / \mathrm{z}$ the mass resolution alone is generally sufficient to univocally attribute a $\mathrm{C}_{\mathrm{m}} \mathrm{H}_{\mathrm{n}}{ }^{+}$or $\mathrm{C}_{\mathrm{m}} \mathrm{H}_{\mathrm{n}} \mathrm{O}_{\mathrm{p}}{ }^{+}$formula, however at higher $\mathrm{m} / \mathrm{z}$ more and more elemental combinations are consistent with the same accurate mass within the experimental incertitude. Sometimes, the isotopic pattern can provide useful information to distinguish the two different situations; however, we have not yet performed a systematic investigation but only examined some specific cases that so far seem to support the presence of oxygen-containing molecules rather than fragment ions.

It should be noted that at this level of the data analysis, the presence of fragment ions in the mass defect plot does not really impact the data interpretation. However, in order to extract detailed chemical information from the mass spectra it is required to separate molecular and fragment ions. Developing and validating a method to identify fragment ions is beyond the scope of this paper, but we will address it in the future developments of our work.

\subsection{Sample contamination due to polysiloxanes}

Significant amounts of contaminating organosilicon compounds are occasionally detected by mass defect analysis. In some cases, the contaminated samples can be simply recognized by visual inspection of the wafers, since a white-iridescent layer appears at the wafer surface. The presence of a large concentration of organosilicon compounds often corresponds to a drastic drop of the mass resolution in the contaminated samples, in parallel with the appearance in the mass spectra of new peaks mostly attributed to polysiloxanes fragment ions. This way becomes impossible to extract information from the mass spectrum because polysiloxanes fragment ions drastically alter the typical soot and condensable gas pattern. The main peaks identified and attributed to polysiloxanes are listed in Table 1. The comparative analysis of the samples and a close investigation of the sampling process show that the contamination source is the conductive tubing for aerosol transport used during early tests. The surface reactivity on silicon wafers is quickly ruled out since depositions on titanium wafers are occasionally contaminated as well. Furthermore, polysiloxanes from the conductive tubing produce a significantly different mass pattern than the soot surface reactivity on silicon wafers: the former generates peaks that are mostly attributed to oxygen-containing (polysiloxane) fragment ions as shown in Table 1. The latter are generally characterized by larger mass defect peaks that are attributed to fragment ions with significant lower oxygen content. In any case, replacing the conductive tubing for aerosol transport with Teflon or stainless steel tubing completely removed the contamination source. Silicone conductive tubing is widely used for aerosol transport because they minimize the particle loss, therefore we recommend caution, all the more since this issue was already addressed in the past $^{[27-30]}$. In fact, especially if the transport line is heated (in our case because of the proximity to the sampling probe), polysiloxane desorbed from the tubing can re-adsorb at the particle surface, completely changing the structure (peak list and peak relative intensity) of the mass spectra of contaminated samples.

\subsection{ToF-SIMS vs. L2MS}

The mass spectra obtained with ToF-SIMS and L2MS are compared in Figure 6. The L2MS mass spectrum is characterized by a single mass distribution, spanning the range $m / z \in[150,600]$ and dominated by $m / z=202\left(\mathrm{C}_{16} \mathrm{H}_{10}{ }^{+}\right) . \quad m / z<100$ contains a low 
contribution of fragments of PAHs. Similar mass distributions have been previously reported $^{[31,34]}$. By contrast, the SIMS mass spectrum shows two different peak distributions: the first one at low $\mathrm{m} / \mathrm{z}$ is dominated by ions having intensity rapidly decreasing with $\mathrm{m} / \mathrm{z}$, and a second one covering $m / z \in[150,800]$ features the strongest peaks in $m / z \in[200,300]$. Observations of the former distribution suggest that post-ionization dissociation reactions likely play a prominent role in SIMS measurements.

In the high mass distributions of both mass spectra, the strongest peaks are $12 \mathrm{u}$ spaced and are accompanied by weaker satellite peaks. This distribution is commonly attributed to PAH molecules ${ }^{[35]}$. A closer look to the L2MS mass spectrum shows an alternation of strong and weak groups of peaks. The strongest ones are associated with structures having an even number of carbon atoms and corresponding to Stein's stabilomers ${ }^{[36]}$. The maximum of the distribution in SIMS is slightly shifted to higher masses compared to the L2MS mass spectra. This behavior is likely due to the strong post-ionization dissociation reactions occurring under ion bombardment in the $\mathrm{keV}$ regime. Tyler et al. ${ }^{[37]}$ observed that the signals of small PAH parent ions (naphthalene, anthracene and pyrene) are one order of magnitude less intense than fragment ions in positive SIMS measurements. By contrast, the mass spectrum of coronene is mostly fragment-free ${ }^{[38]}$. For larger PAHs, additional fragmentation peaks are recorded corresponding to the sequential loss of $2 \mathrm{H}$ as also mentioned in ${ }^{[38]}$. The preferential loss of $2 \mathrm{H}$ has also been reported for PAHs during photolysis ${ }^{[39]}$.

The low $\mathrm{m} / \mathrm{z}$ region in L2MS mass spectra is almost signal-free for two main reasons. First, successive optimization steps in our technique ${ }^{[19,20]}$ led to the conclusion that desorption and ionization laser irradiance must be lowered close to the threshold to increase the PAH signal by avoiding fragmentation. Second, resonant one-color, two-photon laser ionization at $266 \mathrm{~nm}(4.66 \mathrm{eV})$ is a very efficient method to selectively ionize PAHs since they have strong $\pi-\pi^{*}$ absorption bands in this spectral region and their ionization potentials are lower than the energy of two photons $(9.32 \mathrm{eV})^{[40,41]}$. On the contrary, we cannot expect to see any aliphatic molecules which do not absorb at this wavelength and for which the ionization potentials lie at higher energies ${ }^{[42]}$. We note that extensive discussion can be found in the literature on the presence or absence of the aliphatic compounds in the adsorbed phase of soot particles $^{[43,44]}$.

\section{Conclusions}

In this paper we developed an experimental method to analyze soot and condensable gas produced during flame combustion by ToF-SIMS. We focused on the definition of an analytical protocol including all steps from the soot sampling to the data processing. In particular, we developed a dedicated probe sampling apparatus that enables for high dilution ratio during sampling. We compared sampling using silicone conductive tubing and stainless steel tubing for aerosol transport and we observed that many samples obtained with the former are affected by large amounts of polysiloxanes, which makes any further data reduction nigh impossible. In order to improve the overall quality of the mass spectra, we investigated soot depositions on three different substrates, microfiber glass filters, silicon and titanium wafers, and compared the results with our previous measurements by L2MS. The ultra-flat surface resulting from depositions on wafers enables for a mass resolution roughly four times larger than microfiber glass filters that in turn makes mass defect analysis possible. Once the substrate-specific peaks are removed, silicon and titanium wafers perform very similarly. However, titanium is the preferred substrate since its surface reactivity byproducts are more easily identified than silicon. The mass spectra are calibrated, smoothed, and aligned. The accurate masses are built into a peak list and identified by mass defect analysis 
and comparative analysis of the depositions on different substrates, and mainly attributed to $\mathrm{C}_{\mathrm{m}} \mathrm{H}_{\mathrm{n}}{ }^{+}$and $\mathrm{C}_{\mathrm{m}} \mathrm{H}_{\mathrm{n}} \mathrm{O}_{\mathrm{p}}{ }^{+}$ions.

The mass spectra obtained from the analysis of the soot deposit are significantly richer in high mass than those obtained from the wafer surface far from the deposit. Such difference can be exploited to get information on the chemical composition of the gas phase: while particles only deposit on the impaction spot, condensable gas deposit all over the wafer surface, including the already deposited soot.

The differences between ToF-SIMS and L2MS are due to the instrument performance and to analytical method. While ToF-SIMS features higher overall sensitivity, mass range and resolving power, the harsh ionization process results in the mass spectra being heavily affected by post ionization dissociation reactions. On the other hand, low-irradiance laser ionization in L2MS enables for almost fragment free mass spectra, while REMPI ionization greatly enhances the detection of few PAHs only.

Future work will focus on the development of a database of samples. In particular, the analysis of a variety of soot samples collected from different flames and reaction times is expected to provide useful information on the kinetic of soot nucleation and surface growth.

\section{Acknowledgements}

This work was supported by the Agence Nationale de la Recherche through the LABEX CAPPA (ANR-11-LABX-0005), the Ministry of Higher Education and Research, Hauts-deFrance Regional Council and European Regional Development Fund (ERDF) through the Contrat de Projets Etat-Region (CPER CLIMIBIO), the H2020 project Portable Nano-Particle Emission Measurement System (PEMs4Nano, Grant Agreement no. 724145) and the international project

SW-0608. 


\section{References}

[1] P. van der Heide, FrontMatter, in Secondary Ion Mass Spectrometry. John Wiley \& Sons, Inc., Hoboken, NJ, USA, 2014, pp. i-xvii.

[2] R. E. Peterson, B. J. Tyler. Analysis of organic and inorganic species on the surface of atmospheric aerosol using time-of-flight secondary ion mass spectrometry (TOF-SIMS). Atmos. Environ. 2002, 36, 6041.

[3] B. Öktem, M. P. Tolocka, B. Zhao, H. Wang, M. V Johnston, M. V Johnston. Chemical species associated with the early stage of soot growth in a laminar premixed ethyleneoxygen-argon flame. Combust. Flame 2005, 142, 364.

[4] H. Wang. Formation of nascent soot and other condensed-phase materials in flames. Proc. Combust. Inst. 2011, 33, 41.

[5] U. Kirchner, R. Vogt, C. Natzeck, J. Goschnick. Single particle MS, SNMS, SIMS, XPS, and FTIR spectroscopic analysis of soot particles during the AIDA campaign. $J$. Aerosol Sci. 2003, 34, 1323.

[6] W. Cheng, L. T. Weng, Y. Li, A. Lau, C. Chan, C. M. Chan. Characterization of sizesegregated aerosols using ToF-SIMS imaging and depth profiling. Surf. Interface Anal. 2014, 46, 480 .

[7] O. B. Popovicheva, C. Irimiea, Y. Carpentier, et al. Chemical Composition of Diesel/Biodiesel Particulate Exhaust by FTIR Spectroscopy and Mass Spectrometry: Impact of Fuel and Driving Cycle. Aerosol Air Qual. Res. 2017, 17, 1717.

[8] A. Faccinetto, K. Thomson, M. Ziskind, C. Focsa. Coupling of desorption and photoionization processes in two-step laser mass spectrometry of polycyclic aromatic hydrocarbons. Appl. Phys. A. 2008, 92, 969.

[9] R. Lemaire, A. Faccinetto, E. Therssen, M. Ziskind, C. Focsa, P. Desgroux. Experimental comparison of soot formation in turbulent flames of Diesel and surrogate Diesel fuels. Proc. Combust. Inst. 2009, 32, 737.

[10] F. Aubriet, V. Carré. Potential of laser mass spectrometry for the analysis of environmental dust particles-A review. Anal. Chim. Acta 2010, 659, 34.

[11] T. R. Dallmann, T. B. Onasch, T. W. Kirchstetter, et al. Characterization of particulate matter emissions from on-road gasoline and diesel vehicles using a soot particle aerosol mass spectrometer. Atmospheric Chem. Phys. 2014, 14, 7585.

[12] A. Faccinetto, C. Focsa, P. Desgroux, M. Ziskind. Progress toward the quantitative analysis of PAHs adsorbed on soot by laser desorption/laser ionization/time-of-flight mass spectrometry. Environ. Sci. Technol. 2015, 49, 10510.

[13] C. R. Shaddix, J. E. Harrington, K. C. Smyth. Quantitative measurements of enhanced soot production in a flickering methane/air diffusion flame. Combust. Flame 1994, 99, 723.

[14] B. Tian, Y. Gao, S. Balusamy, S. Hochgreb. High spatial resolution laser cavity extinction and laser-induced incandescence in low-soot-producing flames. Appl. Phys. B Lasers Opt. 2015, 120, 469. 
[15] C. S. Moreau, E. Therssen, X. Mercier, J. F. Pauwels, P. Desgroux. Two-color laserinduced incandescence and cavity ring-down spectroscopy for sensitive and quantitative imaging of soot and PAHs in flames. Appl. Phys. B Lasers Opt. 2004, 78, 485.

[16] P. Desgroux, X. Mercier, K. A. Thomson. Study of the formation of soot and its precursors in flames using optical diagnostics. Proc. Combust. Inst. 2013, 34, 1713.

[17] C. Betrancourt, F. Liu, P. Desgroux, et al. Investigation of the size of the incandescent incipient soot particles in premixed sooting and nucleation flames of n-butane using LII, HIM, and 1 nm-SMPS. Aerosol Sci. Technol. 2017, 51, 916.

[18] W. Kern. The evolution of silicon wafer cleaning technology. J. Electrochem. Soc. 1990, 137, 1887.

[19] C. Mihesan, M. Ziskind, E. Therssen, P. Desgroux, C. Focsa. Parametric study of polycyclic aromatic hydrocarbon laser desorption. J. Phys. Condens. Matter 2008, 20, 025221.

[20] K. Thomson, M. Ziskind, C. Mihesan, E. Therssen, P. Desgroux, C. Focsa. Influence of the photoionization process on the fragmentation of laser desorbed polycyclic aromatic hydrocarbons. Appl. Surf. Sci. 2007, 253, 6435.

[21] N. Nuns, J. F. Lamonier, J. M. Giraudon, S. Siffert, B. L. Su. ToF-SIMS studies of the $\mathrm{TiO} 2-\mathrm{ZrO} 2$ supported palladium as trace level used in the total oxidation of TCE in humid air. Surf. Interface Anal. 2013, 45, 566.

[22] J. C. Vickerman, D. Briggs. TOF-SIMS: Materials Analysis by Mass Spectrometry. $2^{\text {nd }}$ Edition, IM Publications LLP and Surface Spectra; 2013.

[23] H. Junninen, H. Niska, K. Tuppurainen, J. Ruuskanen, M. Kolehmainen. Methods for imputation of missing values in air quality data sets. Atmos. Environ. 2004, 38, 2895.

[24] Y. An, S. Teng, Y. Pei, J. Qin, X. Li, H. Zhao. An experimental study of polycyclic aromatic hydrocarbons and soot emissions from a GDI engine fueled with commercial gasoline. Fuel 2016, 164, 160.

[25] L. Sleno. The use of mass defect in modern mass spectrometry. J. Mass Spectrom. 2012, 47, 226.

[26] C. A. Hughey, C. L. Hendrickson, R. P. Rodgers, A. G. Marshall, K. Qian. Kendrick mass defect spectrum: a compact visual analysis for ultrahigh-resolution broadband mass spectra. Anal. Chem. 2001, 73, 4676.

[27] B. Apicella, A. Ciajolo, M. Milian, C. Galmes, A. A. Herod, R. Kandiyoti. Oligomeric carbon and siloxane series observed by matrix-assisted laser desorption/ionisation and laser desorption/ionisation mass spectrometry during the analysis of soot formed in fuelrich flames. Rapid Commun. Mass Spectrom. 2004, 18, 331.

[28] J. Schneider, S. Weimer, F. Drewnick, et al. Mass spectrometric analysis and aerodynamic properties of various types of combustion-related aerosol particles. Int. J. Mass Spectrom. 2006, 258, 37.

[29] Y. Yu, M. Liz Alexander, V. Perraud, et al. Contamination from electrically conductive silicone tubing during aerosol chemical analysis. Atmos. Environ. 2009, 43, 2836.

[30] M. T. Timko, Z. Yu, J. Kroll, et al. Sampling Artifacts from Conductive Silicone Tubing. Aerosol Sci. Technol. 2009, 43, 855. 
[31] A. Faccinetto, P. Desgroux, M. Ziskind, E. Therssen, C. Focsa. High-sensitivity detection of polycyclic aromatic hydrocarbons adsorbed onto soot particles using laser desorption/laser ionization/time-of-flight mass spectrometry: An approach to studying the soot inception process in low-pressure flames. Combust. Flame 2011, 158, 227.

[32] P. Desgroux, A. Faccinetto, X. Mercier, T. Mouton, D. Aubagnac Karkar, A. El Bakali. Comparative study of the soot formation process in a nucleation and a sooting low pressure premixed methane flame. Combust. Flame 2017, 184, 153.

[33] H. Bladh, N.-E. Olofsson, T. Mouton, et al. Probing the smallest soot particles in lowsooting premixed flames using laser-induced incandescence. Proc. Combust. Inst. 2015, $35,1843$.

[34] B. Apicella, A. Carpentieri, M. Alfè, et al. Mass spectrometric analysis of large PAH in a fuel-rich ethylene flame. Proc. Combust. Inst. 2007, 31 I, 547.

[35] K. H. Homann. Fullerenes and soot formation - New pathways to large particles in flames. Angew. Chem. Int. Ed. Engl. 1998, 37, 2435.

[36] S. E. Stein, a. Fahr. High-temperature stabilities of hydrocarbons. J. Phys. Chem. 1985, 89,3714 .

[37] B. J. Tyler, S. Dambach, S. Galla, R. E. Peterson, H. F. Arlinghaus. Investigation of the utility of laser-secondary neutral mass spectrometry for the detection of polyaromatic hydrocarbons in individual atmospheric aerosol particles. Anal. Chem. 2012, 84, 76.

[38] T. Stephan, E. K. Jessberger, C. H. Heiss, D. Rost. TOF-SIMS analysis of polycyclic aromatic hydrocarbons in Allan Hills 84001. Meteorit. Planet. Sci. 2003, 38, 109.

[39] S. P. Ekern, A. G. Marshall, J. Szczepanski, M. Vala. Photon-induced Complete Dehydrogenation of Putative Interstellar Polycyclic Aromatic Hydrocarbon Cations: Coronene and Naphtho[2,3-[CLC]a[/CLC]]pyrene. Astrophys. J. 1997, 488, L39.

[40] F. Mühlberger, R. Zimmermann, A. Kettrup. A Mobile Mass Spectrometer for Comprehensive On-Line Analysis of Trace and Bulk Components of Complex Gas Mixtures: Parallel Application of Laser-Based Ionization Methods VUV-Single-Photon Ionization, Resonant Multiphoton Ionization, and Laser-Induced Electron Impact Ionization. Anal. Chem. 2001, 73, 3590.

[41] O. P. Haefliger, R. Zenobi. Laser mass spectrometric analysis of polycyclic aromatic hydrocarbons with wide wavelength range laser multiphoton ionization spectroscopy. Anal. Chem. 1998, 70, 2660.

[42] Y. Kato, T. Wakabayashi, T. Momose. A mass spectroscopic study of laser vaporized graphite in $\mathrm{H} 2$ and $\mathrm{D} 2$ gases: The stability of $\mathrm{C} 2 \mathrm{nH} 2(\mathrm{n}=2-5)$ and $\mathrm{C} 10$. Chem. Phys. Lett. 2004, 386, 279.

[43] J. P. Cain, J. Camacho, D. J. Phares, H. Wang, A. Laskin. Evidence of aliphatics in nascent soot particles in premixed ethylene flames. Proc. Combust. Inst. 2011, 33, 533.

[44] B. Öktem, M. P. Tolocka, B. Zhao, H. Wang, M. V. Johnston. Chemical species associated with the early stage of soot growth in a laminar premixed ethylene-oxygenargon flame. Combust. Flame 2005, 142, 364. 


\begin{tabular}{|c|c|c|c|c|c|}
\hline$M_{\mathrm{r}} / \mathrm{u}$ & Assignment & $M_{\mathrm{r}} / \mathrm{u}$ & Assignment & $M_{\mathrm{r}} / \mathrm{u}$ & Assignment \\
\hline 27.977 & $\mathrm{Si}^{+}$ & 86.972 & $\mathrm{Si}_{2} \mathrm{CH}_{3} \mathrm{O}^{+}$ & 191.002 & $\mathrm{Si}_{3} \mathrm{C}_{4} \mathrm{H}_{11} \mathrm{O}_{3}^{+}$ \\
\hline 28.985 & $\mathrm{SiH}^{+}$ & 100.988 & $\mathrm{Si}_{2} \mathrm{C}_{2} \mathrm{H}_{5} \mathrm{O}^{+}$ & 191.038 & $\mathrm{Si}_{3} \mathrm{C}_{5} \mathrm{H}_{15} \mathrm{O}_{2}^{+}$ \\
\hline 29.993 & $\mathrm{SiH}_{2}^{+}$ & 101.996 & $\mathrm{Si}_{2} \mathrm{C}_{2} \mathrm{H}_{6} \mathrm{O}^{+}$ & 205.054 & $\mathrm{Si}_{3} \mathrm{C}_{6} \mathrm{H}_{17} \mathrm{O}_{2}^{+}$ \\
\hline 31.000 & $\mathrm{SiH}_{3}{ }^{+}$ & 102.967 & $\mathrm{Si}_{2} \mathrm{CH}_{3} \mathrm{O}_{2}^{+}$ & 206.025 & $\mathrm{Si}_{3} \mathrm{C}_{5} \mathrm{H}_{14} \mathrm{O}_{3}{ }^{+}$ \\
\hline 40.985 & $\mathrm{SiCH}^{+}$ & 103.004 & $\mathrm{Si}_{2} \mathrm{C}_{2} \mathrm{H}_{7} \mathrm{O}_{2}^{+}$ & 207.033 & $\mathrm{Si}_{3} \mathrm{C}_{5} \mathrm{H}_{15} \mathrm{O}_{3}^{+}$ \\
\hline 41.993 & $\mathrm{SiCH}_{2}{ }^{+}$ & 115.004 & $\mathrm{Si}_{2} \mathrm{C}_{3} \mathrm{H}_{7} \mathrm{O}_{2}^{+}$ & 209.049 & $\mathrm{Si}_{3} \mathrm{C}_{5} \mathrm{H}_{17} \mathrm{O}_{3}^{+}$ \\
\hline 43.000 & $\mathrm{SiCH}_{3}{ }^{+}$ & 117.019 & $\mathrm{Si}_{2} \mathrm{C}_{3} \mathrm{H}_{9} \mathrm{O}_{2}^{+}$ & 221.049 & $\mathrm{Si}_{3} \mathrm{C}_{6} \mathrm{H}_{17} \mathrm{O}_{3}{ }^{+}$ \\
\hline 43.972 & $\mathrm{SiO}^{+}$ & 131.035 & $\mathrm{Si}_{2} \mathrm{C}_{4} \mathrm{H}_{11} \mathrm{O}^{+}$ & 221.085 & $\mathrm{Si}_{3} \mathrm{C}_{7} \mathrm{H}_{21} \mathrm{O}_{2}^{+}$ \\
\hline 44.980 & $\mathrm{SiOH}^{+}$ & 132.006 & $\mathrm{Si}_{2} \mathrm{C}_{3} \mathrm{H}_{8} \mathrm{O}_{2}^{+}$ & 265.020 & $\mathrm{Si}_{4} \mathrm{C}_{6} \mathrm{H}_{17} \mathrm{O}_{4}^{+}$ \\
\hline 57.016 & $\mathrm{SiC}_{2} \mathrm{H}_{5}^{+}$ & 133.014 & $\mathrm{Si}_{2} \mathrm{C}_{3} \mathrm{H}_{9} \mathrm{O}_{2}^{+}$ & 265.057 & $\mathrm{Si}_{4} \mathrm{C}_{7} \mathrm{H}_{21} \mathrm{O}_{3}^{+}$ \\
\hline 57.987 & $\mathrm{SiCH}_{2} \mathrm{O}^{+}$ & 133.050 & $\mathrm{Si}_{2} \mathrm{C}_{4} \mathrm{H}_{13} \mathrm{O}_{2}^{+}$ & 266.028 & $\mathrm{Si}_{4} \mathrm{C}_{6} \mathrm{H}_{18} \mathrm{O}_{4}^{+}$ \\
\hline 58.995 & $\mathrm{SiCH}_{3} \mathrm{O}^{+}$ & 147.03 & $\mathrm{Si}_{2} \mathrm{C}_{4} \mathrm{H}_{11} \mathrm{O}_{2}^{+}$ & 267.036 & $\mathrm{Si}_{4} \mathrm{C}_{6} \mathrm{H}_{19} \mathrm{O}_{4}{ }^{+}$ \\
\hline 61.011 & $\mathrm{SiCH}_{5} \mathrm{O}^{+}$ & 147.066 & $\mathrm{Si}_{2} \mathrm{C}_{5} \mathrm{H}_{15} \mathrm{O}_{2}^{+}$ & 267.072 & $\mathrm{Si}_{4} \mathrm{C}_{7} \mathrm{H}_{23} \mathrm{O}_{3}{ }^{+}$ \\
\hline 71.949 & $\mathrm{Si}_{2} \mathrm{O}^{+}$ & 159.012 & $\mathrm{Si}_{3} \mathrm{C}_{4} \mathrm{H}_{11} \mathrm{O}^{+}$ & 279.072 & $\mathrm{Si}_{4} \mathrm{C}_{8} \mathrm{H}_{23} \mathrm{O}_{3}^{+}$ \\
\hline 72.957 & $\mathrm{Si}_{2} \mathrm{HO}^{+}$ & 160.991 & $\mathrm{Si}_{3} \mathrm{C}_{3} \mathrm{H}_{9} \mathrm{O}_{2}^{+}$ & 281.052 & $\mathrm{Si}_{4} \mathrm{C}_{7} \mathrm{H}_{21} \mathrm{O}_{4}{ }^{+}$ \\
\hline 73.011 & $\mathrm{SiC}_{2} \mathrm{H}_{5} \mathrm{O}^{+}$ & 175.007 & $\mathrm{Si}_{3} \mathrm{C}_{4} \mathrm{H}_{11} \mathrm{O}_{2}^{+}$ & 323.008 & $\mathrm{Si}_{5} \mathrm{C}_{7} \mathrm{H}_{19} \mathrm{O}_{5}^{+}$ \\
\hline 74.055 & $\mathrm{SiC}_{3} \mathrm{H}_{10}{ }^{+}$ & 176.986 & $\mathrm{Si}_{3} \mathrm{C}_{3} \mathrm{H}_{9} \mathrm{O}_{3}^{+}$ & 324.987 & $\mathrm{Si}_{5} \mathrm{C}_{6} \mathrm{H}_{17} \mathrm{O}_{6}^{+}$ \\
\hline 75.027 & $\mathrm{SiC}_{2} \mathrm{H}_{7} \mathrm{O}^{+}$ & 189.022 & $\mathrm{Si}_{3} \mathrm{C}_{5} \mathrm{H}_{13} \mathrm{O}_{2}^{+}$ & 355.070 & $\mathrm{Si}_{5} \mathrm{C}_{9} \mathrm{H}_{27} \mathrm{O}_{5}^{+}$ \\
\hline
\end{tabular}

Table 1. Identified masses, up to $m / z=355$, of polysiloxane fragment ions and assigned molecular formulae. 

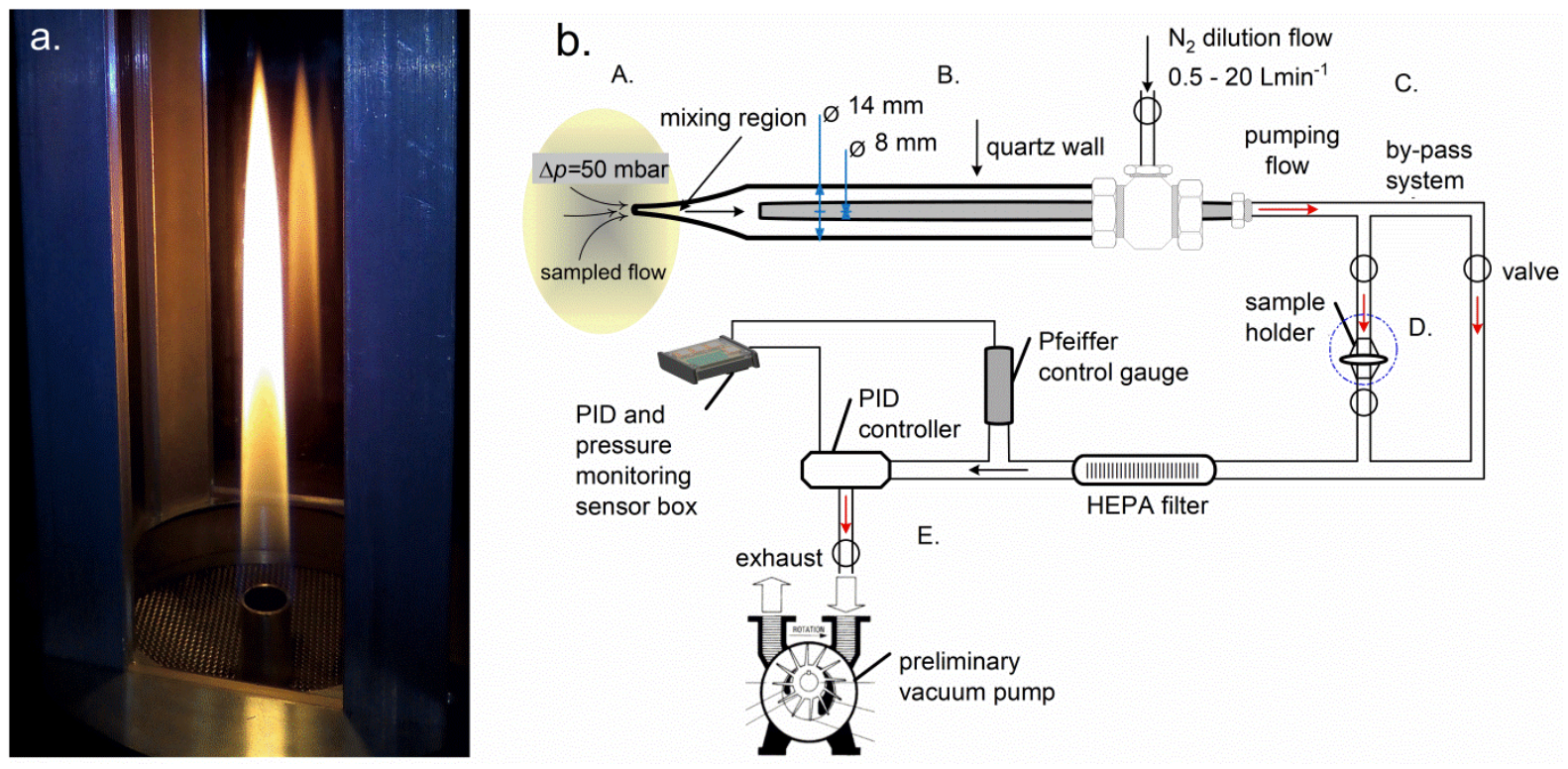

Figure 1. (a) Investigated flame (DIF-S) surrounded by a shielding quartz windowed chimney. During the soot sampling procedure one of the windows is removed for the sampling probe insertion. (b) Overview of the experimental setup used for soot and condensable gas sampling (A) from laboratory diffusion flames. The quartz probe (B) consists of two concentric tubes through which the sampling flow is stabilized. The dilution nitrogen enters the top port, flows between the two quartz tubes up to the probe tip, mixes with the sample flow from the flame and it is removed through a bypass system (C) and impactor (D). The pressure in the line is kept constant using a PID controller and a preliminary vacuum pump (E). 


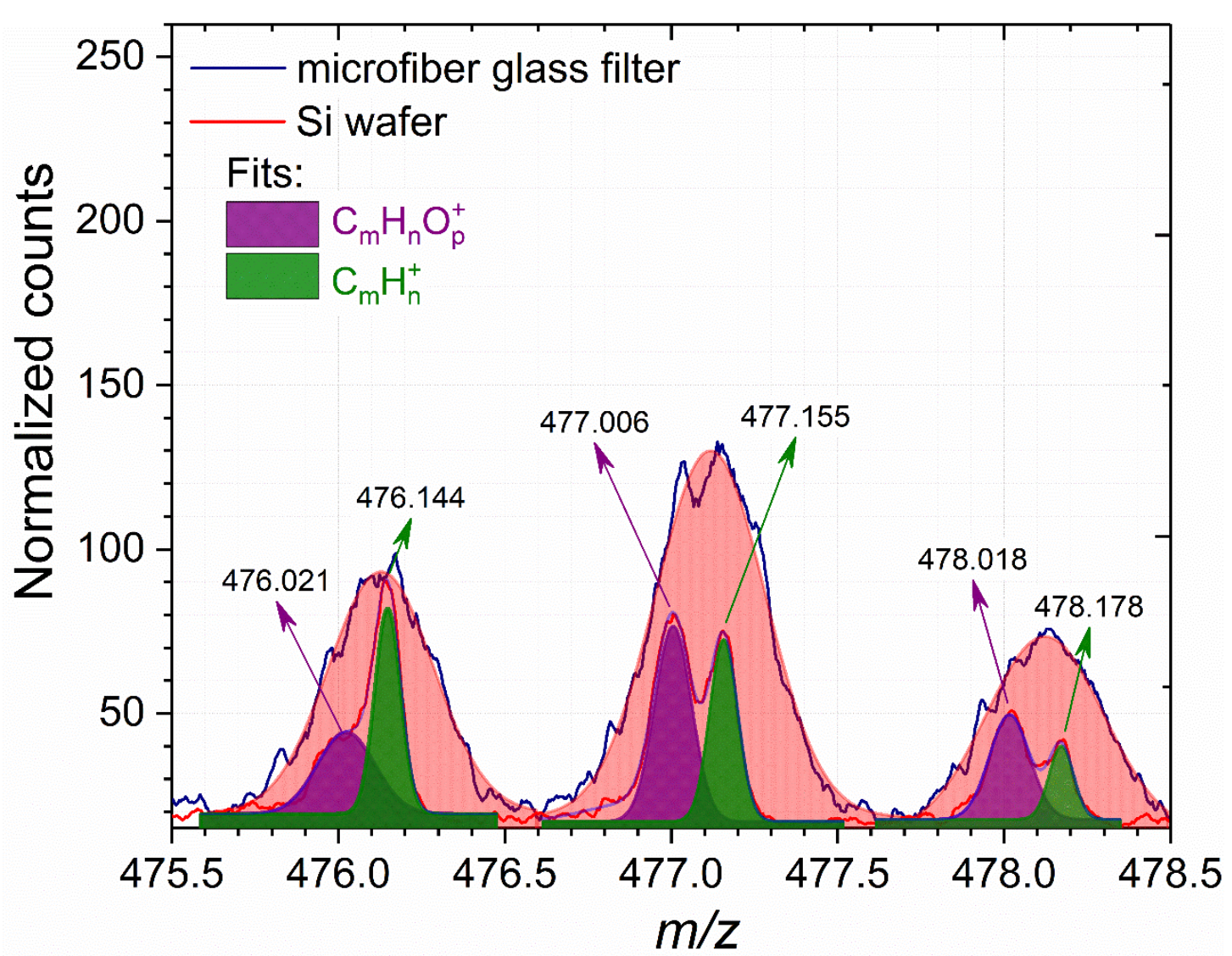

Figure 2. Comparison of mass spectra at $m / z=476-478$ obtained from deposits on glass microfiber filter (dark blue line) and Si wafer (red line). The colored areas below the curves are the Gaussian fits of the deconvoluted peaks. 


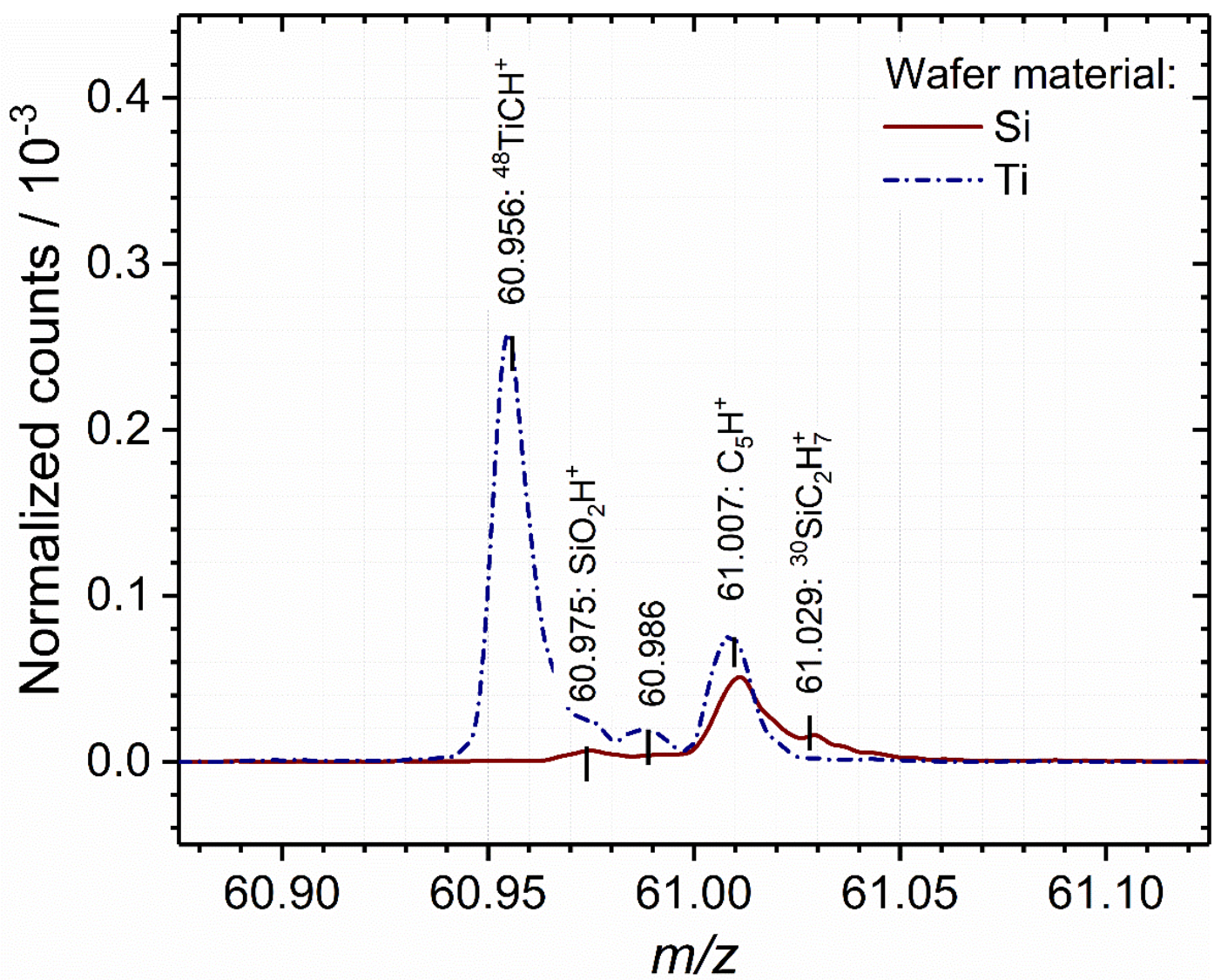

Figure 3. Example of comparative analysis for the identification of unknown compounds. The figure shows $m / z=61$ in the mass spectra obtained from sampling flame DIF-S, $65 \mathrm{~mm} \mathrm{HAB}$, deposition on silicon (solid line) and titanium (dashed line) wafers. The only strong peak occurring in both mass spectra is the one attributed to fragment ion $\mathrm{C}_{5} \mathrm{H}^{+}$. Notice that after normalization by the partial ion count calculated on the peak list, the intensity of the peak $\mathrm{C}_{5} \mathrm{H}^{+}$in the two mass spectra are similar so that no further data manipulation is required. 

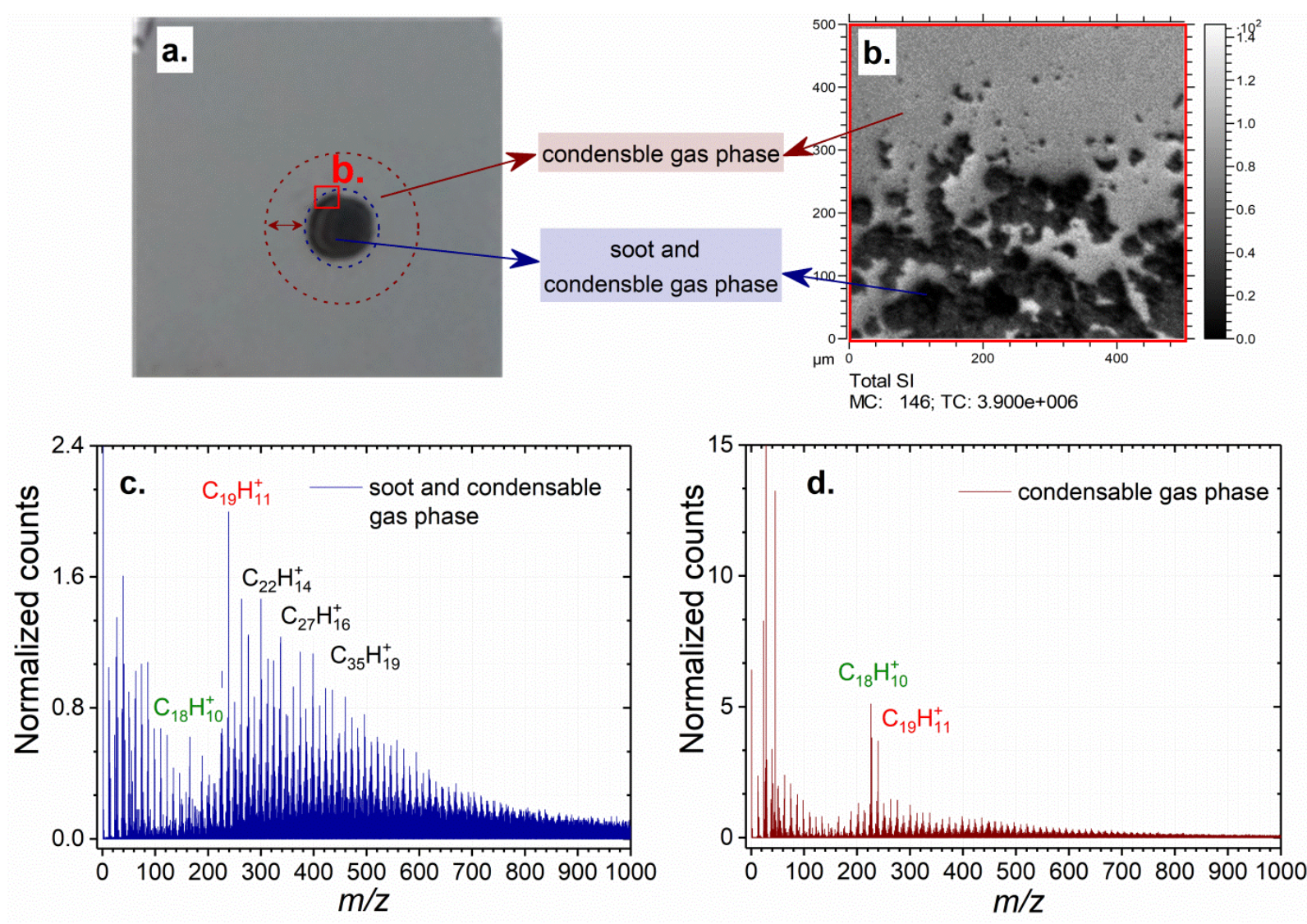

Figure 4. Soot and condensable gas deposition obtained by impaction on wafer (a), and image obtained with the ToF-SIMS integrated optical microscope (b) corresponding to the region delimited with a red square in (a). Mass spectra obtained from the analysis of the soot deposit ROI (c) and of the condensable gas ROI. Each mass spectrum is obtained from the average of the data collected from 3 different regions. 

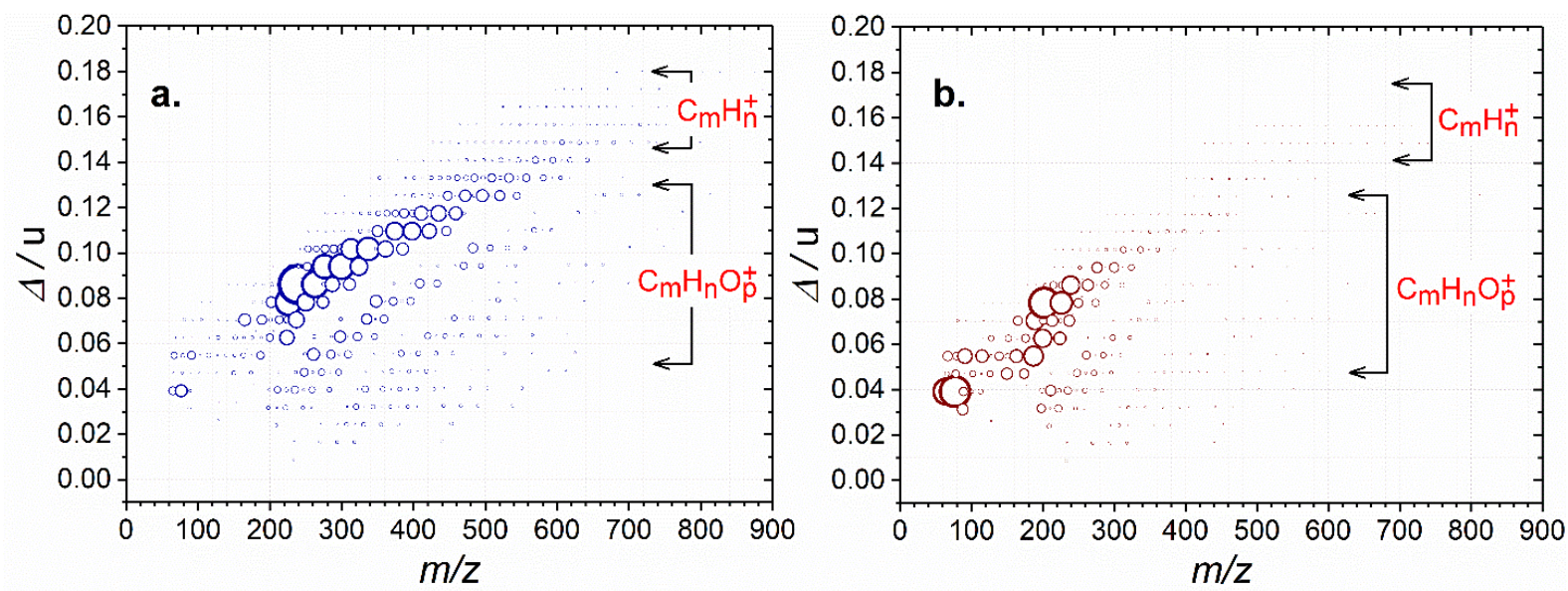

Figure 5. Mass defect plots of soot samples obtained from (a) the soot deposit ROI and (b) the condensable gas ROI. The size of the data points is proportional to the area of the peak normalized to the total ion counts calculated on the selected peak list. 


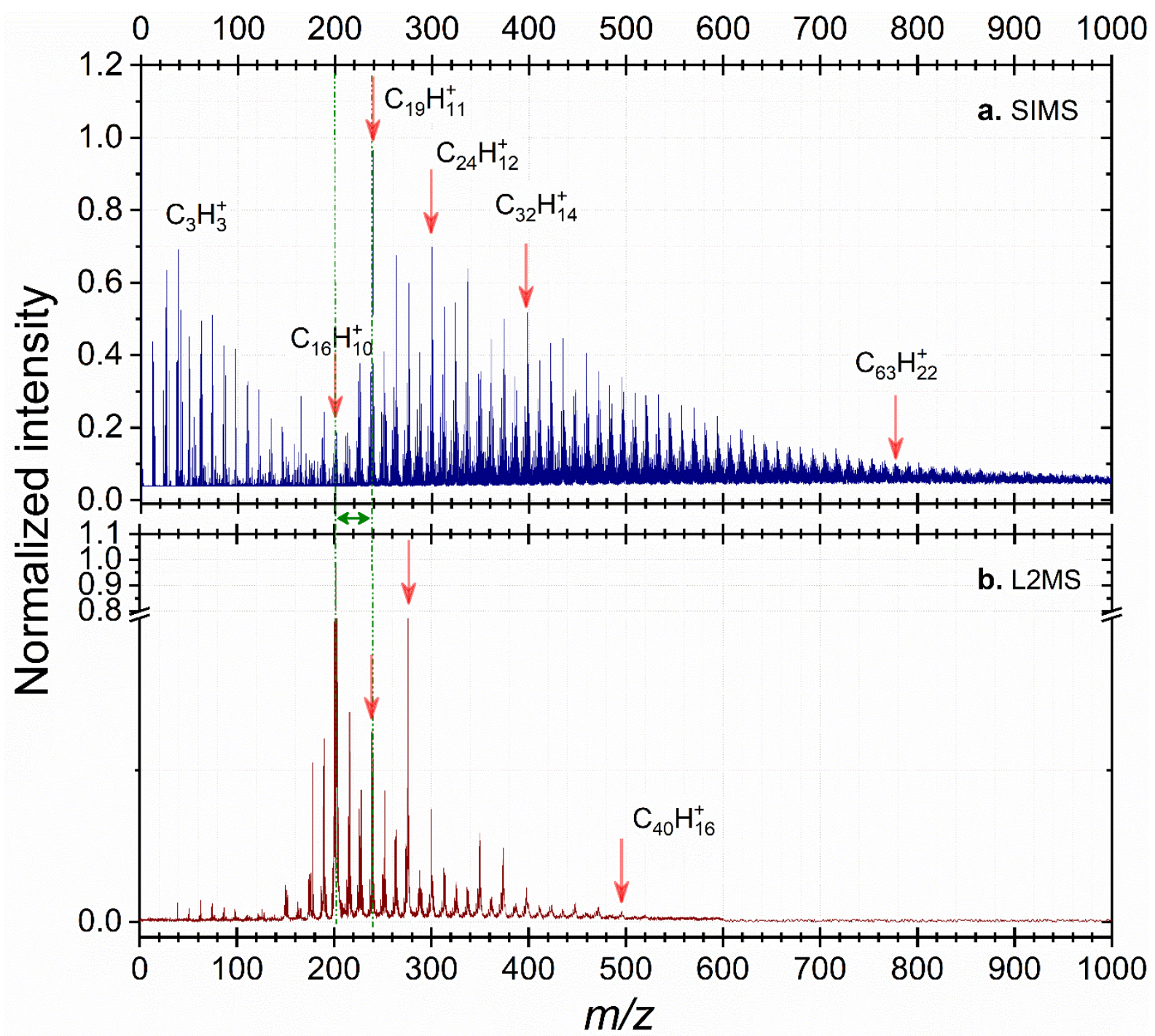

Figure 6. Mass spectra obtained with (a) SIMS in positive polarity and (b) L2MS. The SIMS mass spectrum is obtained from soot deposit on wafer while the L2MS mass spectrum corresponds to soot and condensable gas phase deposited over glass microfiber filter. The L2MS mass spectrum is obtained by irradiating the sample surface with $12.5 \mathrm{~mJ} \mathrm{~cm}^{-2}$ at $266 \mathrm{~nm}$ desorption wavelength, and at a delayed time the expansion plume is

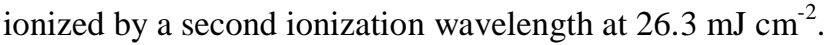

